\title{
“THE BLOOMSBURY COMPANION TO COGNITIVE LINGUISTICS": UM PANORAMA CONTEMPORÂNEO DA LINGUÍSTICA COGNITIVA
}

Aline Nardes dos Santos

Doutoranda em Linguística Aplicada pela Universidade do Vale do Rio dos Sinos

(Unisinos) / Bolsista CAPES/Prosuc aline.nardes@gmail.com

Rove Chishman

Doutora em Letras pela Pontifícia Universidade Católica do Rio Grande do Sul (PUCRS) Professora Titular da Universidade do Vale do Rio dos Sinos (Unisinos) / Bolsista

Produtividade do CNPq rove@unisinos.br

\section{RESENHA}

LITTLEMORE, Jeanette; TAYLOR, John. (orgs.). The Bloomsbury companion to Cognitive Linguistics. London: Bloomsbury, 2014.

O complexo e efervescente movimento da Linguística Cognitiva (LC), que tem se expandido consideravelmente nas últimas décadas, desdobra-se em múltiplas interfaces teóricas e busca articular-se cada vez mais com áreas de conhecimento interessadas nas facetas sociocognitivas da linguagem. Em virtude de tais ramificações, torna-se uma tarefa difícil reunir todas as abordagens que se inserem no escopo da LC em apenas uma definição. Exemplo disso são as criativas metáforas criadas por linguistas cognitivos para dar conta dessa heterogeneidade: para Geeraerts (2006), a LC é um arquipélago de teorias, de modo que cada ilha constitui-se em uma abordagem relativamente autônoma que partilha de certos pressupostos com as demais. Já para Evans, Bergen e Zinken (2007), a Linguística Cognitiva é um bolo em camadas: cada fatia é uma teoria diferente 
que partilha as mesmas camadas epistemológicas com os demais pedaços. Independentemente da metáfora escolhida, o desafio de expressar as convergências e as peculiaridades das abordagens linguístico-cognitivas, sem perder de vista o todo do movimento, é um desafio que poucos se dispõem a enfrentar. Nomeadamente, no cenário internacional, destacamos a obra de Evans e Green (2006), intitulada "Cognitive Linguistics: an introduction"; o manual de Geeraerts e Cuyckens (2006), "The Oxford Handbook of Cognitive Linguistics"; bem como o guia de leitura de Evans, Bergen e Zinken (2007), denominado "The Cognitive Linguistics Reader". No cenário editorial mais recente, a editora Bloomsbury lança esta obra intitulada "The Bloomsbury Companion to Cognitive Linguistics", de Jeanette Littlemore e John Taylor, que se incumbe da complexa tarefa de atualizar os leitores acerca dos desdobramentos contemporâneos da LC.

Para compreendermos o escopo da obra, é importante considerarmos a trajetória dos autores. Segundo as informações da própria obra, Jeanette Littlemore é pesquisadora da área de Linguística Aplicada e atua no Departamento de Língua Inglesa da Universidade de Birmigham. Em virtude de seu interesse em ensino de línguas, a pesquisadora tem investigado o potencial de conceitos linguístico-cognitivos no ensino de língua adicional, principalmente questões relativas à metáfora conceptual e às diferenças culturais entre projeções metafóricas que impactam no ensino de línguas. Por sua vez, John Taylor é professor da Universidade de Otago (Nova Zelândia), atuando principalmente nas interfaces gramaticais da Linguística Cognitiva. É bastante renomado no campo por seus manuais que introduzem noções centrais à LC, como a obra "Linguistic Categorization" (TAYLOR, 2003), sobre o escopo da categorização como fenômeno sociocognitivo; e o manual "Cognitive Grammar" (TAYLOR, 2002), que explora a teoria da Gramática Cognitiva, postulada por Ronald Langacker (1987; 2008). 
Segundo o site da Bloomsbury, a editora diferencia as categorias editoriais companion e handbook da seguinte forma: enquanto seus handbooks sistematizam os pressupostos de uma disciplina, apresentando seu estado da arte, os títulos da categoria companion se incumbem de fornecer guias acessíveis relativos a novos campos de investigação. Levando em conta tal distinção, é possível inferir que o propósito primordial da obra de Taylor e Littlemore seria mapear principais áreas emergentes no âmbito da Linguística Cognitiva. No entanto, os autores realizam, por meio da introdução da obra, um apanhado primoroso dos principais postulados que sustentam a Linguística Cognitiva, de modo que o leitor menos familiarizado com a área possa compreender suficientemente como esse movimento teórico-epistemológico tem se organizado na atualidade. Nesse sentido, estruturalmente, o primeiro capítulo traz os principais conceitos que definem a LC, situando postulados como experiencialismo; primazia do uso nas teorias de gramática cognitiva; operações de perspectivação conceptual; categorização; metáfora, metonímia e esquemas imagéticos; dentre outros aspectos.

Na segunda parte da obra (capítulo 2), são abordadas as principais teorias da LC, dando-se ênfase a seus autores mais renomados - estrutura que se assemelha, por exemplo, a manuais como o de Geeraerts e Cuyckens (2006) -, separando-se em subcapítulos as teorias postuladas por Ronald Langacker (subcapítulo 2.1), George Lakoff (2.2), Adele Goldberg (2.3), Gilles Fauconnier (2.4), Michael Tomasello (2.5) e Catherine Bybee (2.6). Nesse sentido, pontuamos a inovação dos autores ao incluírem a relevante contribuição de Bybee à área - a qual não é destacada nos conhecidos manuais que mencionamos no início desta resenha -, dada a valorosa exploração de dados empíricos em seus trabalhos, levando conta evidências baseadas em corpora. 
A terceira seção da obra se diferencia da segunda por focar em temas, e não em autores, de modo a indicar como as contribuições de obras seminais exploradas na segunda seção foram desenvolvidas em trabalhos contemporâneos, mais especificamente os desdobramentos das teorias atinentes à metáfora conceptual (subcapítulo 3.1), à metonímia (3.2), à corporificação e à sua relação com projeções metafóricas (3.3); bem como às perspectivas linguístico-cognitivas relativas a expressões multivocabulares (3.4), variação linguística (3.5), poética cognitiva (3.6), ideologia (3.7) e fonologia (3.8). Observamos que, embora alguns desses temas sejam bastante explorados em obras introdutórias anteriores - tais como a poética cognitiva e as perspectivas contemporâneas da metáfora - o "Bloomsbury Companion" se preocupa em contextualizar temas menos abordados que têm sido cruciais às investigações em LC hoje, bem como às interfaces que se estabelecem em prol desses fenômenos. Por exemplo, os estudos em fonologia, tão negligenciados em outros manuais, são contemplados no subcapítulo que encerra essa terceira parte, o qual evidencia a importância dos processos cognitivos e da corporificação para a compreensão da organicidade fonológica de uma língua.

Levando em conta o conceito de companion trazido pela editora Bloomsbury, acreditamos que a quarta e última parte da obra cumpra mais diretamente a função de contextualizar campos emergentes da Linguística Cognitiva que têm fundamentado novas descobertas, quais sejam: pesquisas baseadas em corpus (subcapítulo 4.1), aplicações de pressupostos da LC para além da linguística (4.3) aquisição da linguagem e ensino (4.3) e aplicações da teoria da metáfora em um contexto de aconselhamento pedagógico (4.4). Esse capítulo enfatiza, desse modo, o escopo crescente da LC, de modo a contribuir para contextos não relacionados à pesquisa linguística: a obra nos indica que, após ter se 
valido de descobertas de outras áreas para postular novos caminhos de pesquisa em Linguística nos anos 1970-1980, a área passa a alimentar hoje outros campos com suas próprias descobertas, estabelecendo uma retroalimentação teórico-metodológica constante.

De modo geral, assim como a própria Linguística Cognitiva preconiza o caráter difuso das categorias, a organização do "Bloomsbury Companion of Cognitive Linguistics" parece não se enquadrar meramente na categoria compendium, que a editora insiste em diferenciar de handbook: para delinear novas perspectivas de pesquisa em LC, os autores tiveram de recuperar o estado da arte do campo, introduzindo devidamente os conceitos que unem as ilhas do arquipélago - ou as camadas do bolo - linguístico-cognitivo. Assim, ao construir a obra sobre tais alicerces, os autores convidam leitores menos especializados a apreciar confortavelmente o livro, ao mesmo tempo em que atualizam o leitor mais familiarizado com a área sobre as novas tendências investigativas em LC.

\section{Referências}

EVANS, Vyvian; BERGEN, Benjamin; ZINKEN, Jörg. The cognitive linguistics reader. London/Oakville: Equinox Publishing, 2007.

EVANS, Vyvian; GREEN, Melanie. Cognitive linguistics: an introduction. Edimburg: Edinburgh University Press, 2006.

GEERAERTS, Dirk. Introduction: a rough guide to cognitive linguistics. In: GEERAERTS, Dirk (ed.). Cognitive linguistics: basic readings. Berlin: Mouton de Gruyter, 2006. p. 1-28.

GEERAERDTS, Dirk; CUYCKENS, Hubert. (orgs.). The Oxford Handbook of Cognitive Linguistics. New York: Oxford University Press, 2007.

LANGACKER, Ronald. Foundations of cognitive grammar: theoretical prerequisites. Stanford: Stanford University Press, 1987. 
LANGACKER, Ronald. Cognitive grammar: a basic introduction. New York: Oxford University Press, 2008.

TAYLOR, John. Cognitive grammar. New York: Oxford University Press, 2002.

TAYLOR, John. Linguistic categorization. New York: Oxford University Press, 2009.

Recebido em 15 de setembro de 2018.

Aceite em 20 de novembro de 2018.

\footnotetext{
'Disponível em: <https://www.bloomsbury.com/uk/academic/reference/companions-and-handbooks/>.
} 